Corrigendum to

\title{
"An efficient regional energy-moisture balance model for simulation of the Greenland Ice Sheet response to climate change" published in The Cryosphere, 4, 129-144, 2010
}

\author{
A. Robinson ${ }^{1,2}$, R. Calov ${ }^{1}$, and A. Ganopolski ${ }^{1}$ \\ ${ }^{1}$ Potsdam Institute for Climate Impact Research, Potsdam, Germany \\ ${ }^{2}$ University of Potsdam, Potsdam, Germany
}

We regret that some unintentional omissions exist in the published version of our article. Our research relied heavily on comparison to other models, and it is very important to acknowledge the contributions of others. We would therefore like to add to the following acknowledgements.

Acknowledgements. We are very grateful to J. Ettema for providing the RACMO2/GR data and to J. Box for providing the PolarMM5 data used in this study.
Furthermore, the following reference of Ettema et al. (2009) should appear in the reference list.

Ettema, J., van den Broeke, M. R., van Meijgaard, E., van de Berg, W. J., Bamber, J. L., Box, J. E., and Bales, R. C.: Higher surface mass balance of the Greenland ice sheet revealed by high-resolution climate modeling, Geophys. Res. Lett., 36, L12501, doi:10.1029/2009GL038110, 2009. 